\title{
Appendiceal neoplasm risk associated with complicated acute appendicitisa population based study
}

\section{Lietzen, Elina}

2019-01

Lietzen , E , GrÖnroos , J M , Mecklin , J-P , Leppäniemi , A , Nordström , P , Rautio , T , Rantanen , T , Sand , J , Paajanen , H , Kaljonen , A \& Salminen , P 2019 , ' Appendiceal neoplasm risk associated with complicated acute appendicitisa population based study ' , International Journal of Colorectal Disease , vol. 34 , no. 1 , pp. 39-46 . https://doi.org/10.1007/s00384-018-3156-x

http://hdl.handle.net/10138/302369

https://doi.org/10.1007/s00384-018-3156-x

publishedVersion

Downloaded from Helda, University of Helsinki institutional repository.

This is an electronic reprint of the original article.

This reprint may differ from the original in pagination and typographic detail.

Please cite the original version. 


\title{
Appendiceal neoplasm risk associated with complicated acute appendicitis—a population based study
}

\author{
Elina Lietzén ${ }^{1,2}$ • Juha M. Grönroos ${ }^{1,2}$ • Jukka-Pekka Mecklin ${ }^{3,4}$ • Ari Leppäniemi ${ }^{5,6}$ • Pia Nordström ${ }^{7,8} \cdot$ Tero Rautio $^{9,10}$. \\ Tuomo Rantanen ${ }^{11,12,13}$. Juhani Sand ${ }^{14}$. Hannu Paajanen ${ }^{15} \cdot$ Anne Kaljonen $^{16}$ • Paulina Salminen ${ }^{1,2}$
}

Accepted: 27 August 2018 / Published online: 22 September 2018

(C) Springer-Verlag GmbH Germany, part of Springer Nature 2018

\begin{abstract}
Purpose Appendiceal tumors are rare, but high neoplasm rates have been reported at interval appendectomy after periappendicular abscess. Non-operative management of uncomplicated acute appendicitis has shown promising results. The data on appendiceal tumor incidence and presentation among acute appendicitis patients is limited, especially in patient cohorts differentiating between uncomplicated and complicated acute appendicitis. Objective was to assess appendiceal tumor incidence and tumor association to appendicitis in patients with uncomplicated and complicated acute appendicitis.

Methods This nationwide population-based registry study was conducted from 2007 to 2013 . The Finnish Cancer Registry and the National Institute for Health Registry were used to combine data on all appendiceal tumors and acute appendicitis diagnosis with medical reports evaluated at eight study hospitals.

Results Altogether, 840 appendiceal tumors were identified, and out of these, 504 patient reports were reviewed, including 472 patients in this study. Tumor was diagnosed at appendectomy for suspected acute appendicitis in 276 patients (58\%). In the whole study, histologically acute appendicitis and tumor were both present in 53\% $(n=250)$, and out of these, $41 \%(n=102)$ were complicated and 59\% $(n=148)$ uncomplicated acute appendicitis. The associated tumor risk was significantly higher in complicated acute appendicitis compared with uncomplicated cases $(3.24 \%$ vs. $0.87 \%, p<0.001)$. Overall tumor prevalence among acute appendicitis patients was $1.24 \%$.

Conclusions Appendiceal tumor prevalence in acute appendicitis was low. Tumor risk was significantly higher in complicated acute appendicitis compared with uncomplicated acute appendicitis. The risk of missed appendiceal tumors related to antibiotic therapy of uncomplicated acute appendicitis is very low.
\end{abstract}

Keywords Acute appendicitis · Uncomplicated acute appendicitis · Complicated acute appendicitis · Non-operative treatment Appendectomy $\cdot$ Appendiceal neoplasm

Elina Lietzén

elina.lietzen@tyks.fi

1 Division of Digestive Surgery and Urology, Department of Digestive Surgery, Turku University Hospital, Kiinanmyllynkatu 4-8, 20520 Turku, Finland

2 University of Turku, Turku, Finland

3 Department of Surgery, Jyväskylä Central Hospital and Sport and Health Sciences, Jyväskylä, Finland

4 University of Jyväskylä, Jyväskylä, Finland

5 Department of Gastrointestinal Surgery, Helsinki University Central Hospital, Helsinki, Finland

6 University of Helsinki, Helsinki, Finland

7 Division of Surgery, Gastroenterology and Oncology, Tampere University Hospital, Tampere, Finland
8 University of Tampere, Tampere, Finland

9 Department of Surgery, Division of Gastroenterology, Oulu University Hospital, Oulu, Finland

10 University of Oulu, Oulu, Finland

11 Department of Surgery, Seinäjoki Central Hospital, Seinäjoki, Finland

12 Department of Surgery, Kuopio University Hospital, Kuopio, Finland

13 University of Kuopio, Kuopio, Finland

14 Health and Medical Services, Päijät-Häme Joint Authority for Health and Wellbeing, Lahti, Finland

15 Department of Surgery, Mikkeli Central Hospital, Mikkeli, Finland

16 The Department of Biostatistics, University of Turku, Turku, Finland 


\section{Introduction}

The treatment paradigm of uncomplicated acute appendicitis may be changing as promising results with antibiotic therapy have been reported, and operative treatment may be unnecessary for the majority of uncomplicated acute appendicitis patients $[1-3]$. In order to optimize and tailor the treatment for acute appendicitis, precise and accurate diagnostic tools, such as computed tomography $(\mathrm{CT})$ are required. As CT has high sensitivity in diagnosing acute appendicitis, it has become the golden standard in right lower quadrant abdominal pain differential diagnosis [4]. Uncomplicated acute appendicitis may also resolve spontaneously without even antibiotics, let alone surgery [5]. Non-operative management of uncomplicated acute appendicitis has also been shown to reduce treatment costs [6]. In cases of complicated acute appendicitis with a formation of a circumscribed abscess, the need for interval appendectomy after initial successful conservative treatment has also been questioned as the risk of appendicitis recurrence is quite low between 5 and 20\% [7]. However, there are some more recent studies reporting an alarming rate of appendiceal neoplasms detected at interval appendectomy in patients with previous periappendicular abscess $[8,9]$, especially regarding patients over the age of 40 years $[8,10]$.

Appendiceal tumors are rare, usually incidental findings most often detected at histological evaluation of the removed appendix. Appendiceal neoplasm rate varies from 0.7 to $2.5 \%$ of appendectomy specimens in several large appendectomy series [7, 11-13]. With the development of precise diagnostic capabilities like CT, appendiceal tumors may increasingly be suspected on CT $[14,15]$. However, most of the CT signs related to appendiceal tumors are unspecific and preoperative diagnosis of an appendiceal tumor on CT can be obscured by signs of acute or secondary inflammation [14]. Appendiceal tumors are a heterogeneous group of diseases ranging from typical neuroendocrine tumors (NET) to adenocarcinomas, including all the varieties within this spectrum. The pathological classification and terminology of appendiceal tumors has undergone major changes over the last decades [16-18]. In addition, most studies on appendiceal tumors are retrospective case report compilations, further contributing to possible diagnostic, therapeutic, and also prognostic uncertainty related to neoplasms of the appendix. Further, the majority of appendiceal tumor data has previously been based on retrospective single-center studies of low patient numbers with limited generalizability. In an attempt to overcome these limitations, we assessed appendiceal tumors through a population-based study relying on combining the national cancer surveillance and surgical procedures data with actual patient medical records enabling assessment at both population and patient level. To our knowledge, there is only a limited number of recent population-based registry studies published on appendiceal tumors [16, 18-27].
The aim of this study was to evaluate both the incidence of appendiceal tumors among acute appendicitis patients and the possible tumor association to both uncomplicated and complicated acute appendicitis, using both national population-based cancer surveillance and surgical procedure data.

\section{Methods}

A nationwide population-based registry study was performed to assess all diagnosed appendiceal tumors in Finland from 2007 to 2013. This study was approved by the Turku University Hospital ethical committee. Diagnoses were categorized according to the World Health Organization International Classification of Disease year 2010 classification (ICD-10) [28]. The study population of appendiceal primary tumors was collected from the Finnish Cancer Registry (FCR), which is responsible for maintaining a nationwide database on all cancer cases in Finland. All hospitals and laboratories are required by law to provide the FCR with information on all new diagnosed cancers. The accuracy of FCR is very reliable as it covers over $99 \%$ of all solid tumors diagnosed in Finland. From the patient population diagnosed with a histologically proven appendiceal primary tumor, we collected hospital medical record data on patients treated at eight study hospitals: all five university hospitals (Helsinki, Tampere, Turku, Kuopio, and Oulu) and three larger central hospitals (Jyväskylä, Mikkeli, and Lahti). These eight hospitals were included in the study for practical data retrieving reasons in order to be able to collect adequate nationwide data, comprising the majority of the study population. The population of these study hospitals represented $70.1 \%$ (study hospital population $3,843,871$ /population of the whole country $5,487,308$ ) of the whole population in Finland. In all patients, the medical record data collection included patient demographics, tumor diagnosis, related imaging and operative findings, tumor histology, and associated treatments. Operative findings and histological reports were reviewed, in order to reliably differentiate uncomplicated and complicated acute appendicitis diagnosis. Complicated acute appendicitis was defined as perforation or a periappendiceal abscess. Unclear cases were assessed by another senior surgeon with blinded evaluation. Some of the medical records were not available due to lack of common hospital district databases at the time of the study and patients with unavailable data were excluded from the study. All included patients had complete medical data records available and all patient information contained in these datasets was non-identifiable at analysis.

All eligible patients with available data were divided into three groups based on how the appendiceal tumor was diagnosed. In group 1, the appendiceal tumor was detected at or after (histology) surgery for suspected acute appendicitis (emergency appendectomy or interval appendectomy); in group 2, the appendiceal tumor was diagnosed at or after (histology) surgery performed for other indications (incidental 
appendectomy); and in group 3, the appendiceal tumor was diagnosed at preoperative imaging.

In order to assess the true prevalence of appendiceal tumors among all acute appendicitis patients, we collected information from the National Institute for Health and Welfare (NIHW) registry to gather data on both acute appendicitis diagnosis and appendectomies during the study period. Dates of admission and discharge, discharge diagnosis, surgical procedure, and demographic data of the patient are by law recorded in NIHW registry for every hospitalized patient nationwide. In analyzing the patients in the NIHW registry, no additional tumors not presented in FCR were identified underlining the almost perfect coverage of appendiceal tumors in the FCR database.

\section{Statistical methods}

The differences in background variables between the three groups (group 1: appendiceal tumor was detected at or after (histology) surgery for suspected acute appendicitis; group 2: at surgery performed for other indications; group 3: at preoperative imaging) were tested for a numeric variable (age) with one-way analysis of variance and for categorical variables using chi-square test. The risk of having appendiceal tumor was calculated using the chi-square test and odds ratio with 95\% confidence limits. All of the statistical analyses were performed using SAS version 9.4 (SAS Institute Inc., Cary, NC, USA).

\section{Results}

A total of 840 appendiceal primary tumor patients were identified from FCR database and $504(60 \%)$ patients were treated in the hospital districts of the eight study hospitals. Altogether, 472 appendiceal tumor patients with available diagnostic and clinical data were included in this study (Fig. 1). In the whole study group, preoperative imaging was performed for $58 \%$ ( $n=293 / 472)$ of the patients, and the main imaging modality $(n=231)$ was contrast-enhanced CT scan. Out of these 472 patients, the appendiceal tumor was diagnosed at surgery either for suspected acute appendicitis or interval appendectomy after primary conservative treatment of periappendicular abscess in $276(58 \%)$ patients (group 1) at a mean age of 46 years, at abdominal surgery for other indications in 142 (30\%) patients (group 2) at a mean age of 60 years, or at any preoperative imaging in $54(11 \%)$ patients (group 3) at a mean age of 59 years. Detailed patient demographics, clinical and diagnostic findings, histology, and additional treatments according to these study groups $1-3$ are presented in Table 1.

Patients undergoing surgery for suspected acute appendicitis (group 1), 92\% $(n=254 / 276)$ underwent appendectomy, and 7\% $(n=20 / 276)$ underwent a more extensive bowel resection. The majority of the patients $(87 \%, 241 / 276)$ underwent an emergency operation. Out of these 276 patients,
$86 \%(n=235)$ had acute appendicitis at histology resulting in a negative appendectomy rate of $14 \%$. In group $1,53 \%(n=$ 145 ) underwent diagnostic imaging, and none of the tumors were suspected on preoperative imaging. At surgery, a tumor was macroscopically suspected in $11 \%(n=29)$ of the operations, and 12 of these 29 cases were interval appendectomies.

In group 2 undergoing surgery for other indications than suspected acute appendicitis, 77\% $(n=110 / 142)$ of the patients underwent elective surgery. Out of these, 74 patients are for gynecological indications ( 72 for suspicion of a gynecological tumor and 2 for suspected pelvic endometriosis). In addition, there were four emergency gynecological operations due to suspected pelvic inflammation. Four patients undergoing elective surgery were diagnosed with a periappendicular abscess and complicated acute appendicitis at surgery and histology. Three out of these four patients were operated on due to suspicion of gynecological tumor and one for suspected caecal tumor. Out of the 32 emergency procedures in this group, seven of the patients had acute appendicitis at surgery and histology. In the whole patient group $2,66 \%(n=94)$ underwent preoperative imaging, and none of the appendiceal tumors were suspected preoperatively.

In group 3 with tumor suspicion on preoperative imaging, $91 \%$ of the patients $(n=49 / 54)$ underwent elective surgery. Out of all 54 patients, only four (7\%) had acute appendicitis. In preoperative imaging, $74 \%(n=40)$ of group 3 patients were accurately diagnosed with a tumor. In two patients, the imaging overestimated, and in nine patients, underestimated the tumor staging, when compared to operative and histological findings. In three patients, the disease was disseminated and no operation was performed, in two patients, appendiceal tumor histology was obtained by radiological tumor biopsy and in one patient at autopsy.

During the study period, there were altogether 19,976 patients with acute appendicitis diagnosis but without appendiceal tumor identified in the eight study hospitals, and the NIHW registry (Fig. 1) resulting in an appendiceal tumor prevalence of $1.24 \%$ $(p<0.001)$ in the acute appendicitis patient population. There were altogether 250 patients with both acute appendicitis and an appendiceal tumor based on both histology and surgical finding (Fig. 1.). Out of these, 102 (41\%) patients had complicated acute appendicitis and 148 (59\%) had uncomplicated acute appendicitis. The complicated acute appendicitis cases included 66 patients with a periappendiceal abscess and 36 perforated acute appendicitis cases. Out of the 66 patients with periappendiceal abscess, 29 patients underwent an interval appendectomy and 37 patients were operated on in an acute care setting. The appendiceal tumor risk was significantly higher in complicated acute appendicitis compared with uncomplicated acute appendicitis $(3.24 \%$ vs. $0.87 \%, p<0.001)$. The odds ratio $(\mathrm{OR})$ for having an appendiceal tumor in complicated acute appendicitis was 3.83 (CI95\% 2.96-4.93). A separate subgroup analysis of tumor risk associated with periappendiceal abscess patients $(n=66)$ also showed a significantly higher tumor risk compared with 
Fig. 1 Patient inclusion from The Finnish Cancer Registry (FCR) and The National Institute for Health and Welfare Registry (NIHW) between years 2007 and 2013

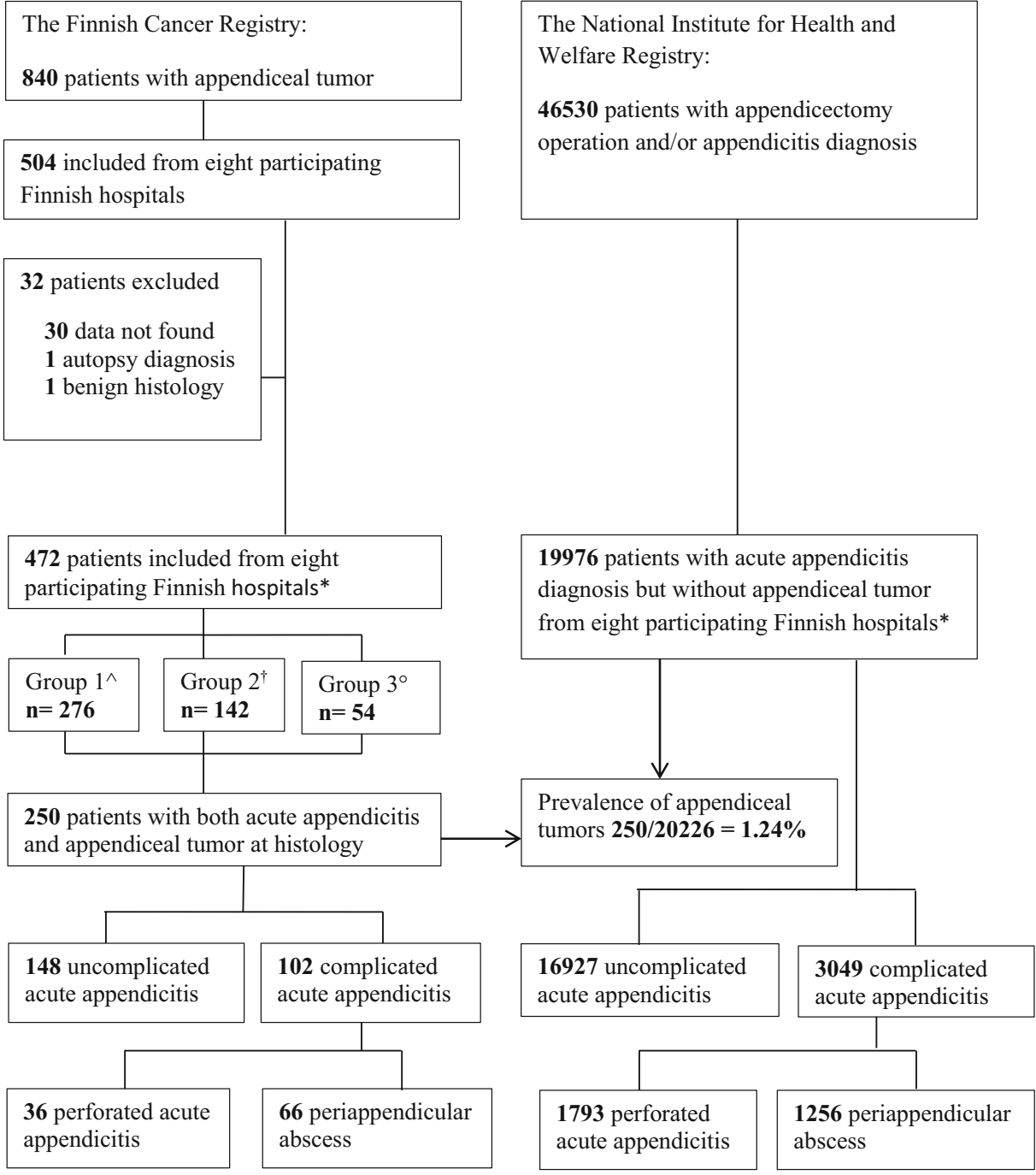

*Eight participating Finnish hospitals: University hospitals of Helsinki, Tampere, Turku, Kuopio, and Oulu, Central hospitals of Jyväskylä, Mikkeli, Lahti

Appendiceal tumor was found: ^ $\mathrm{Group} 1$ : at surgery for suspected acute appendicitis,

${ }^{\dagger}$ Group 2: at surgery done for other indications and ${ }^{\circ}$ Group 3: at preoperative imaging uncomplicated acute appendicitis $(4.99 \%$ vs. $0.87 \%, p<0.001)$. The OR for having an appendiceal tumor in complicated acute appendicitis presenting as periappendicular abscess was $6.01(\mathrm{CI}$ 95\% 4.47-8.08). These comparisons are presented in detail in Table 2. The mean age of all acute appendicitis patients without a tumor in NIHW database was 37 years $(\mathrm{SD} \pm 19.1)$, in uncomplicated acute appendicitis 35 years $(\mathrm{SD} \pm 17.9)$ and in complicated acute appendicitis 44 years $(\mathrm{SD} \pm 43.8)$.

In the whole patient cohort of 472 appendiceal tumor histology, $49 \%(n=232)$ were NETs, $11 \%(n=52)$ mixed adenoneuroendocrine carcinomas (MANEC) or goblet cell tumors, $14 \%(n=65)$ mucinous tumors or pseudomyxomas, and $26 \%$ $(n=123)$ adenocarcinomas. In the whole patient population $49 \%$ of tumors were NETs, but in patients operated on for suspected acute appendicitis (group 1), the NET proportion was higher $(61 \%)$. In group 1, 39\% (109/276) of patients had a more malignant tumor histology other than NET. Of these 109 patients,
$57 \%(n=62)$ of the patients had complicated acute appendicitis, 35 patients had uncomplicated acute appendicitis, 11 patients had no inflammation of the appendix, and in 1 patient, the appendicitis could not be histologically determined. In group 1, $14 \%$ of patients $(n=34)$ did not have acute appendicitis at histology; $82 \%(n=28)$ out of these tumors were NETs, $15 \%(n=$ 5) were adenocarcinomas, and 1 patient had pseudomyxoma. According to histology or surgical finding, 78\% (42/54) of group 3 patients had a local lymph node metastasis or disseminated disease, whereas metastatic disease was present in $19 \%$ in group $1(51 / 276)$ and in $53 \%$ in group $2(75 / 142)$.

\section{Discussion}

In this study, the overall appendiceal tumor prevalence of $1.24 \%$ among patients with acute appendicitis was low. Of 
Table 1 The Finnish Cancer Registry (FCR) database from eight participating hospitals $(n=472)$, patient demographics, clinicopathological characteristics, and treatment regimens

\begin{tabular}{|c|c|c|c|c|}
\hline & $\begin{array}{l}\text { Group } 1 \\
n=276\end{array}$ & $\begin{array}{l}\text { Group } 2 \\
n=142\end{array}$ & $\begin{array}{l}\text { Group } 3 \\
n=54\end{array}$ & $p$ \\
\hline Age, years & & & & $<0.001$ \\
\hline Mean & $45.7 \pm 18.7$ & $59.6 \pm 15.2$ & $59.2 \pm 12.7$ & \\
\hline Range & $9-94$ & $11-97$ & $27-85$ & \\
\hline Gender & & & & $<0.001$ \\
\hline Men & $120(43 \%)$ & $40(28 \%)$ & $33(61 \%)$ & \\
\hline Women & $156(57 \%)$ & $102(72 \%)$ & $21(39 \%)$ & \\
\hline Preoperative imaging & $n=145(53 \%)$ & $n=94(66 \%)$ & $n=54(100 \%)$ & $<0.001$ \\
\hline CT with iv contrast & 105 & 78 & $48(89 \%)$ & \\
\hline CT without contrast & 1 & 4 & $1(2 \%)$ & \\
\hline Ultrasound & 38 & 3 & $1(2 \%)$ & \\
\hline MRI & 1 & 1 & $4(7 \%)$ & \\
\hline X-ray & - & 7 & - & \\
\hline Surgery & $n=276$ & $n=142$ & $n=51$ & $<0.001$ \\
\hline Elective & $35(13 \%)$ & $110(77 \%)$ & $49(91 \%)$ & \\
\hline Emergency & $241(87 \%)$ & $32(23 \%)$ & $2(4 \%)$ & \\
\hline No surgery & - & - & $3(5 \%)$ & \\
\hline Macroscopic tumor suspicion & $n=276$ & $n=142$ & $n=54$ & $<0.001$ \\
\hline No & $244(89 \%)$ & $71(50 \%)$ & $6(11 \%)$ & \\
\hline Yes & $29(11 \%)$ & $65(46 \%)$ & $45(83 \%)$ & \\
\hline Unclear $^{*}$ & $3(1 \%)$ & $6(4 \%)$ & $3(6 \%)$ & \\
\hline Operation & $n=276$ & $n=142$ & $n=51$ & $<0.001$ \\
\hline Appendectomy & $176(64 \%)$ & $61(43 \%)$ & $5(9 \%)$ & \\
\hline Laparoscopic appendectomy & $78(28 \%)$ & $17(12 \%)$ & $7(13 \%)$ & \\
\hline Ileocecal resection & $12(4 \%)$ & $19(13 \%)$ & $2(4 \%)$ & \\
\hline Right hemicolectomy & $8(3 \%)$ & $24(17 \%)$ & $17(31 \%)$ & \\
\hline HIPEC & & & $6(11 \%)$ & \\
\hline Other & $2(0.7 \%)$ & $21(15 \%)$ & $14(26 \%)$ & \\
\hline Acute appendicitis ${ }^{\dagger}$ & $n=276$ & $n=142$ & $n=54$ & $<0.001$ \\
\hline No & $39(14 \%)$ & $127(90 \%)$ & $44(81 \%)$ & \\
\hline Uncomplicated & $142(51 \%)$ & $5(3 \%)$ & $1(2 \%)$ & \\
\hline Complicated & $93(34 \%)$ & $6(4 \%)$ & $3(6 \%)$ & \\
\hline Unclear ${ }^{*}$ & $2(0.7 \%)$ & $4(3 \%)$ & $6(11 \%)$ & \\
\hline Tumor histology & $n=276$ & $n=142$ & $n=54$ & $<0.001$ \\
\hline NET & $167(61 \%)$ & $58(41 \%)$ & $7(13 \%)$ & \\
\hline MANEC, goblet cell & $36(13 \%)$ & $15(11 \%)$ & $1(2 \%)$ & \\
\hline Adenocarsinoma & $64(23 \%)$ & $42(30 \%)$ & $17(31 \%)$ & \\
\hline Pseudomyksoma peritonei & $9(3 \%)$ & $27(19 \%)$ & $29(54 \%)$ & \\
\hline Metastasis $^{\dagger}$ & $n=276$ & $n=142$ & $n=51$ & $<0.001$ \\
\hline No & $225(82 \%)$ & $67(47 \%)$ & $9(17 \%)$ & \\
\hline Local & $10(4 \%)$ & $3(2 \%)$ & $5(9 \%)$ & \\
\hline Disseminated & $41(15 \%)$ & $72(51 \%)$ & $37(69 \%)$ & \\
\hline Additional operation & $n=111(40 \%)$ & $n=41(29 \%)$ & $n=19(35 \%)$ & $<0.001$ \\
\hline Ileocecal resection & 15 & & 2 & \\
\hline Right hemicolectomy & 85 & 12 & 3 & \\
\hline HIPEC & 6 & 20 & 6 & \\
\hline Other & 5 & 9 & 8 & \\
\hline
\end{tabular}

Group 1: appendiceal tumor was found at surgery for suspected acute appendicitis, group 2: at surgery done for other indications, group 3: at preoperative imaging

$C T$ computed tomography, MRI magnetic resonance imaging, HIPEC hyperthermic intraperitoneal chemotherapy, NET neuroendocrine tumor, MANEC mixed adeno-neuroendocrine carcinoma

* No histology or surgical report available

${ }^{\dagger}$ Based on histological and surgical classification

all patients with both acute appendicitis and an appendiceal tumor, $41 \%(n=102)$ were complicated and 59\% $(n=148)$ were uncomplicated acute appendicitis cases. The risk of an appendiceal tumor was statistically significantly higher in patients with complicated acute appendicitis compared to uncomplicated acute appendicitis (3.24\% vs. $0.87 \%)$. The risk was even higher in a subgroup analysis comparing complicated acute appendicitis presenting with periappendiceal abscess to uncomplicated acute appendicitis (4.99\% vs. $0.87 \%)$.

Tumors of the appendix are incidental and rare. In many retrospective patient cohorts evaluating histopathology of the appendectomy specimens, the reported appendiceal tumor rate 
Table 2 To estimate the risk of having appendiceal tumor among acute appendicitis patients, we compared patients with appendiceal tumor and acute appendicitis from FCR register data to patients with acute appendicitis diagnosis in NIHW register. Comparison was done between uncomplicated and complicated acute appendicitis and uncomplicated acute appendicitis and complicated acute appendicitis presenting as periappendiceal abscess

\begin{tabular}{llll}
\hline \multicolumn{3}{c}{ Appendiceal tumor } & \\
\cline { 2 - 3 } & No & \multirow{2}{*}{ Yes $^{\dagger}$} & Total \\
\hline $\begin{array}{l}\text { Uncomplicated } \\
\text { appendicitis }\end{array}$ & $16,927(99.13 \%)$ & $148(0.87 \%)^{*}$ & 17,075 \\
Complicated appendicitis & $3049(96.76 \%)$ & $102(3.24 \%)^{*}$ & 3151 \\
Total & $19,976(98.76 \%)$ & $250(1.24 \%)^{*}$ & 20,226 \\
Uncomplicated & $16,927(99.13 \%)$ & $148(0.87 \%)^{*}$ & 17,075 \\
$\quad$ appendicitis & $1256(95.01 \%)$ & $66(4.99 \%)^{*}$ & 1322 \\
Periappendiceal abscess & $18,183(98.84 \%)$ & $214(11.63 \%)^{*}$ & 18,397 \\
Total & & & \\
\hline${ }^{\circ}$ NIHW register & & & \\
${ }^{\dagger}$ FCR register & & & \\
${ }^{*}$ NIHW and FCR register patients & & \\
${ }^{*} p<0.0001$ & & &
\end{tabular}

varies between $0.7-1.7 \%$ [29-31].These retrospective patient series do not differentiate the two different forms of acute appendicitis. Tumor rate in the randomized APPAC trial [1] comparing appendectomy and antibiotic therapy in the treatment of uncomplicated acute appendicitis was $1.5 \%$ in accordance with large histopathological appendectomy series [31]. According to a systematic review [7], the rate of malignant tumors diagnosed with acute appendicitis and an inflammatory mass was similar to tumor rates in uncomplicated acute appendicitis series [1]. However, contradictory alarming rates of appendiceal neoplasms have been reported in patients presenting with an appendiceal inflammatory mass varying from 10 to $29 \%$ [8-10, 12]. These results are in line with our study as the tumor risk for complicated acute appendicitis was significantly higher compared with patients with uncomplicated acute appendicitis. Tumor risk was even more prominent in patients with acute appendicitis presenting with periappendiceal abscess. According to two systematic reviews and meta-analysis [7, 32], initial non-operative management of periappendiceal abscess patients is superior with decreased complication and reoperation rates compared with emergency appendectomy. There is still major controversy regarding the necessity of an interval appendectomy after successful nonoperative treatment of periappendicular abscess [7, 32]. However, there are some recent studies reporting significant rate of appendiceal neoplasms detected at interval appendectomy in patients with previous periappendiceal abscess, especially regarding patients over 40 years $[8-10,12]$. These and our study results highlight the need for accurate differential diagnosis between uncomplicated and complicated acute appendicitis and consideration of interval appendectomy after initial nonoperative treatment of periappendiceal abscess.
Based on epidemiological studies [33] and accumulating data $[1,3]$, we now know that uncomplicated and complicated acute appendicitis are two different diseases and this is also evident when evaluating appendiceal tumor incidence in acute appendicitis patient population [12]. Approximately 25\% of acute appendicitis cases present as complicated acute appendicitis [33]. Increasing evidence from randomized trials suggests that the majority of patients with uncomplicated acute appendicitis can be treated safely with antibiotics with low tumor rates avoiding unnecessary surgery resulting in decreased morbidity and cost savings $[1,3,6]$. The markedly lower tumor rate associated with uncomplicated acute appendicitis is of vital clinical importance as non-operative management of uncomplicated appendicitis is one its way of becoming one of the treatment options for uncomplicated acute appendicitis $[1,3,34]$ as the appendiceal tumors are not generally suspected preoperatively $[30,35]$. This is in line with our results as none of the tumors in this study were suspected preoperatively in patients operated on for suspected acute appendicitis, and in only $11 \%$ of cases, the tumor was suspected macroscopically during operation.

Clinical identification of appendiceal tumor patients preoperatively seems to be very challenging, even though some risk factors have been identified, such as advanced age, multiple comorbidities, atypical presentation, and complicated appendicitis [13]. In a large retrospective patient cohort [30], 80\% of appendiceal tumors presented with a periappendicular abscess. The lack of preoperative diagnostic tools for detecting appendiceal tumors further emphasize the role of preoperative imaging, as the differential diagnosis between uncomplicated and complicated acute appendicitis is essential in both evaluating the treatment options, and also, regarding the tumor risk. Differential diagnosis between these two forms acute appendicitis without imaging is not feasible [35]. There is a need for determining CT criteria that could help reliably identify complicated acute appendicitis [4] and also incidental appendiceal neoplasms to ensure their surgical resection [36]. Several CT features suggestive of coexisting appendiceal tumor have been described, but frequently, the radiographic appearance is one of acute appendicitis [36-38]. Sensitivity of tumor diagnosis with CT increases with greater appendiceal diameter and with secondary tumor findings, i.e., metastasis, which [15] is in concurrence with this study as $11 \%$ of tumor patients had a preoperative diagnosis and $78 \%$ out of these had metastatic disease at presentation.

The pathological types and behavior of appendiceal tumors are diverse with both confusing classification and terminology. Recognizing the difference in the clinical presentation and the prognosis of primary appendiceal tumors is essential when evaluating risk of misdiagnosis among acute appendicitis patients. The World Health Organization (WHO) classifies appendiceal tumors in two main groups: NETs and appendiceal carcinomas. The overall survival rate is 
associated with the histologic subtype [39]. The appendiceal NETs belongs to a subgroup of neoplasms, where about $80 \%$ of diagnosis are incidental among patients treated due to acute appendicitis or appendectomy performed for other reasons [28]. NETs are the most common primary tumors of the appendix [17, 28], and in most cases, prognosis is excellent [12]. The more malignant NETs are mixed, phenotype tumors include goblet cell tumors and MANECs reported to represent less than $5 \%$ of primary appendiceal tumors [19]. In this whole patient population, $49 \%$ of tumors were NETs. This proportion was higher $(61 \%)$ in patients operated on for suspected acute appendicitis (group 1), and 39\% (109/276) of patients in group 1 had a more malignant tumor histology other than NET. Of these 109 patients, 57\% $(n=62)$ of the patients had complicated acute appendicitis further supporting the results of this population-based study and the higher tumor risk of complicated acute appendicitis compared with uncomplicated acute appendicitis.

This study has several strengths. To our knowledge, this study is to date the most extensive comparison of appendiceal tumor risk between uncomplicated and complicated acute appendicitis patients. The use of population-based data enhances the generalizability of the findings compared to case reports from single institutions with a defined population. Another strong element of the study is the evaluation of the appendicitis' severity by combining appendectomy's finding with histology instead of solely relying on registry data. A limitation of this study is that we included only patients in eight study hospitals instead of the whole FCR registry data. However, our study hospitals include all university hospitals and largest central hospitals in Finland, thus representing the majority (70.1\%) of both the Finnish population and also the registry data $(60 \%)$ patient population. The minor discrepancy between the proportion of the tumors found at these eight hospitals and the proportion of the Finnish population in these hospital districts most likely has no impact on the study results as the FCR database is very reliable. There is no reason to expect that the excluded patients would differ significantly from those included in the study; the practical reason was based only on the feasibility of the patient medical record collection.

\section{Conclusion}

In conclusion, the prevalence of appendiceal tumor among patients with acute appendicitis was low. Tumor risk was significantly higher in complicated acute appendicitis, especially in patients with periappendicular abscess. However, with the very low incidence of appendiceal tumors associated with uncomplicated acute appendicitis, the risk of missing an appendiceal tumor related to non-operative antibiotic treatment of uncomplicated acute appendicitis is extremely low.
Funding/support This study was supported by a Turku University Hospital Government Research Grant (TYKS EVO Foundation), Paulo Foundation, and Constitution of The Gastroenterological Research Foundation.

\section{Compliance with ethical standards}

Conflict of interest Dr. Salminen has received personal fees for lectures from Merck, Lilly, and Orion Pharma.

\section{References}

1. Salminen P, Paajanen H, Rautio T, Nordstrom P, Aarnio M, Rantanen T et al (2015) Antibiotic therapy vs appendectomy for treatment of uncomplicated acute appendicitis: the APPAC randomized clinical trial. JAMA 313(23):2340-2348

2. Sallinen V, Akl EA, You JJ, Agarwal A, Shoucair S, Vandvik PO, Agoritsas T, Heels-Ansdell D, Guyatt GH, Tikkinen KAO (2016) Meta-analysis of antibiotics versus appendicectomy for nonperforated acute appendicitis. Br J Surg 103(6):656-667

3. Vons C, Barry C, Maitre S, Pautrat K, Leconte M, Costaglioli B, Karoui M, Alves A, Dousset B, Valleur P, Falissard B, Franco D (2011) Amoxicillin plus clavulanic acid versus appendicectomy for treatment of acute uncomplicated appendicitis: an open-label, noninferiority, randomised controlled trial. Lancet 377(9777):15731579

4. Kim HY, Park JH, Lee YJ, Lee SS, Jeon JJ, Lee KH (2017) Systematic review and meta-analysis of CT features for differentiating complicated and uncomplicated appendicitis. Radiology 171260

5. Park HC, Kim MJ, Lee BH (2017) Randomized clinical trial of antibiotic therapy for uncomplicated appendicitis. Br J Surg 104(13): 1785-1790

6. Sippola S, Gronroos J, Tuominen R, Paajanen H, Rautio T, Nordstrom P et al (2017) Economic evaluation of antibiotic therapy versus appendicectomy for the treatment of uncomplicated acute appendicitis from the APPAC randomized clinical trial. Br J Surg 104(10):1355-1361

7. Andersson RE, Petzold MG (2007) Nonsurgical treatment of appendiceal abscess or phlegmon: a systematic review and metaanalysis. Ann Surg 246(5):741-748

8. Wright GP, Mater ME, Carroll JT, Choy JS, Chung MH (2015) Is there truly an oncologic indication for interval appendectomy? Am J Surg 209(3):442-446

9. Furman MJ, Cahan M, Cohen P, Lambert LA (2013) Increased risk of mucinous neoplasm of the appendix in adults undergoing interval appendectomy. JAMA Surg 148(8):703-706

10. Carpenter SG, Chapital AB, Merritt MV, Johnson DJ (2012) Increased risk of neoplasm in appendicitis treated with interval appendectomy: single-institution experience and literature review. Am Surg 78(3):339-343

11. Murphy EM, Farquharson SM, Moran BJ (2006) Management of an unexpected appendiceal neoplasm. Br J Surg 93(7):783-792

12. Teixeira FJR Jr, Couto Netto SDD, Akaishi EH, Utiyama EM, Menegozzo CAM, Rocha MC (2017) Acute appendicitis, inflammatory appendiceal mass and the risk of a hidden malignant tumor: a systematic review of the literature. World J Emerg Surg 12:12

13. Loftus TJ, Raymond SL, Sarosi GA Jr, Croft CA, Smith RS, Efron PA, Moore FA, Brakenridge SC, Mohr AM, Jordan JR (2017) Predicting appendiceal tumors among patients with appendicitis. J Trauma Acute Care Surg 82(4):771-775

14. Whitley S, Sookur P, McLean A, Power N (2009) The appendix on CT. Clin Radiol 64(2):190-199 
15. Pickhardt PJ, Levy AD, Rohrmann CA Jr, Kende AI (2002) Primary neoplasms of the appendix manifesting as acute appendicitis: CT findings with pathologic comparison. Radiology 224(3): 775-781

16. Shaib W, Krishna K, Kim S, Goodman M, Rock J, Chen Z, Brutcher E, Staley CIII, Maithel SK, Abdel-Missih S, el-Rayes BF, Bekaii-Saab T (2016) Appendiceal neuroendocrine, goblet and signet-ring cell tumors: a spectrum of diseases with different patterns of presentation and outcome. Cancer Res Treat 48(2):596604

17. Hsu C, Rashid A, Xing Y, Chiang YJ, Chagpar RB, Fournier KF, Chang GJ, You YN, Feig BW, Cormier JN (2013) Varying malignant potential of appendiceal neuroendocrine tumors: importance of histologic subtype. J Surg Oncol 107(2):136-143

18. Brathwaite S, Yearsley MM, Bekaii-Saab T, Wei L, Schmidt CR, Dillhoff ME et al (2016) Appendiceal mixed adeno-neuroendocrine carcinoma: a population-based study of the surveillance, epidemiology, and end results registry. Front Oncol 6:148

19. McGory ML, Maggard MA, Kang H, O'Connell JB, Ko CY (2005) Malignancies of the appendix: beyond case series reports. Dis Colon Rectum 48(12):2264-2271

20. Benedix F, Reimer A, Gastinger I, Mroczkowski P, Lippert H, Kube R, Study Group Colon/Rectum Carcinoma Primary Tumor (2010) Primary appendiceal carcinoma-epidemiology, surgery and survival: results of a German multi-center study. Eur J Surg Oncol 36(8): 763-771

21. McCusker ME, Cote TR, Clegg LX, Sobin LH (2002) Primary malignant neoplasms of the appendix: a population-based study from the surveillance, epidemiology and end-results program, 1973-1998. Cancer 94(12):3307-3312

22. Smeenk RM, van Velthuysen ML, Verwaal VJ, Zoetmulder FA (2008) Appendiceal neoplasms and pseudomyxoma peritonei: a population based study. Eur J Surg Oncol 34(2):196-201

23. Maggard MA, O'Connell JB, Ko CY (2004) Updated populationbased review of carcinoid tumors. Ann Surg 240(1):117-122

24. Mullen JT, Savarese DM (2011) Carcinoid tumors of the appendix: a population-based study. J Surg Oncol 104(1):41-44

25. Marmor S, Portschy PR, Tuttle TM, Virnig BA (2015) The rise in appendiceal cancer incidence: 2000-2009. J Gastrointest Surg 19(4):743-750

26. van den Heuvel MG, Lemmens VE, Verhoeven RH, de Hingh IH (2013) The incidence of mucinous appendiceal malignancies: a population-based study. Int J Color Dis 28(9):1307-1310

27. Shaib WL, Goodman M, Chen Z, Kim S, Brutcher E, Bekaii-Saab $\mathrm{T}$, et al. (2015) Incidence and survival of appendiceal mucinous neoplasms: a SEER analysis. Am J Clin Oncol

28. Pape UF, Niederle B, Costa F, Gross D, Kelestimur F, Kianmanesh R, Knigge U, Öberg K, Pavel M, Perren A, Toumpanakis C,
O"Connor J, Krenning E, Reed N, O"Toole D, all other Vienna Consensus Conference participants (2016) ENETS consensus guidelines for neuroendocrine neoplasms of the appendix (excluding goblet cell carcinomas). Neuroendocrinology 103(2):144-152

29. Tchana-Sato V, Detry O, Polus M, Thiry A, Detroz B, Maweja S, Hamoir E, Defechereux T, Coimbra C, de Roover A, Meurisse M, Honore $\mathrm{P}$ (2006) Carcinoid tumor of the appendix: a consecutive series from 1237 appendectomies. World J Gastroenterol 12(41): 6699-6701

30. Lee WS, Choi ST, Lee JN, Kim KK, Park YH, Baek JH (2011) A retrospective clinicopathological analysis of appendiceal tumors from 3,744 appendectomies: a single-institution study. Int J Color Dis 26(5):617-621

31. Charfi S, Sellami A, Affes A, Yaïch K, Mzali R, Boudawara TS (2014) Histopathological findings in appendectomy specimens: a study of 24,697 cases. Int J Color Dis 29(8):1009-1012

32. Simillis C, Symeonides P, Shorthouse AJ, Tekkis PP (2010) A meta-analysis comparing conservative treatment versus acute appendectomy for complicated appendicitis (abscess or phlegmon). Surgery 147(6):818-829

33. Livingston EH, Fomby TB, Woodward WA, Haley RW (2011) Epidemiological similarities between appendicitis and diverticulitis suggesting a common underlying pathogenesis. Arch Surg 146(3): $308-314$

34. Hansson J, Körner U, Ludwigs K, Johnsson E, Jönsson C, Lundholm K (2012) Antibiotics as first-line therapy for acute appendicitis: evidence for a change in clinical practice. World J Surg 36(9):2028-2036

35. Lietzen E, Mallinen J, Gronroos JM, Rautio T, Paajanen H, Nordstrom $P$ et al (2016) Is preoperative distinction between complicated and uncomplicated acute appendicitis feasible without imaging? Surgery 160(3):789-795

36. Sagebiel TL, Mohamed A, Matamoros A, Taggart MW, Doamekpor F, Raghav KP, Mann GN, Mansfield PF, Eng C, Royal RE, Foo WC, Ensor JE, Fournier KF, Overman MJ (2017) Utility of appendiceal calcifications detected on computed tomography as a predictor for an underlying appendiceal epithelial neoplasm. Ann Surg Oncol 24(12):3667-3672

37. Bennett GL, Tanpitukpongse TP, Macari M, Cho KC, Babb JS (2009) CT diagnosis of mucocele of the appendix in patients with acute appendicitis. AJR Am J Roentgenol 192(3):W103-W110

38. Hines JJ, Paek GK, Lee P, Wu L, Katz DS (2016) Beyond appendicitis; radiologic review of unusual and rare pathology of the appendix. Abdom Radiol (NY) 41(3):568-581

39. Turaga KK, Pappas SG, Gamblin T (2012) Importance of histologic subtype in the staging of appendiceal tumors. Ann Surg Oncol 19(5):1379-1385 